Medical Geochemistry 

Paolo Censi • Thomas H. Darrah • Yigal Erel Editors

\section{Medical Geochemistry}

Geological Materials and Health

算 Springer 


\author{
Editors \\ Paolo Censi \\ Department of Earth and Marine Sciences \\ University of Palermo \\ Palermo, Italy
}

Yigal Erel

Institute of Earth Sciences

The Hebrew University

Jerusalem, Israel

\author{
Thomas H. Darrah \\ Division of Earth and Ocean Sciences \\ Nicholas School of the Environment \\ Duke University \\ Durham, NC, USA
}

ISBN 978-94-007-4371-7

DOI 10.1007/978-94-007-4372-4

Springer Dordrecht Heidelberg New York London

Library of Congress Control Number: 2013932871

(C) Springer Science+Business Media Dordrecht 2013

This work is subject to copyright. All rights are reserved by the Publisher, whether the whole or part of the material is concerned, specifically the rights of translation, reprinting, reuse of illustrations, recitation, broadcasting, reproduction on microfilms or in any other physical way, and transmission or information storage and retrieval, electronic adaptation, computer software, or by similar or dissimilar methodology now known or hereafter developed. Exempted from this legal reservation are brief excerpts in connection with reviews or scholarly analysis or material supplied specifically for the purpose of being entered and executed on a computer system, for exclusive use by the purchaser of the work. Duplication of this publication or parts thereof is permitted only under the provisions of the Copyright Law of the Publisher's location, in its current version, and permission for use must always be obtained from Springer. Permissions for use may be obtained through RightsLink at the Copyright Clearance Center. Violations are liable to prosecution under the respective Copyright Law.

The use of general descriptive names, registered names, trademarks, service marks, etc. in this publication does not imply, even in the absence of a specific statement, that such names are exempt from the relevant protective laws and regulations and therefore free for general use.

While the advice and information in this book are believed to be true and accurate at the date of publication, neither the authors nor the editors nor the publisher can accept any legal responsibility for any errors or omissions that may be made. The publisher makes no warranty, express or implied, with respect to the material contained herein.

Printed on acid-free paper

Springer is part of Springer Science+Business Media (www.springer.com) 


\section{Preface}

According to Goldschmidt, Geochemistry describes elemental distributions in geochemical spheres, assessing their abundances and rules driving element fractionations therein. Since dawn of civilization and more so since the Industrial Revolution, at the same time, the development of analytical techniques allow us to exposures can significant human health, especially interactions between solids (or products coming from their dissolutions) and different interfaces within the human body (respiratory, gastrointestinal, skin). These phenomena the recognition of this role. This solid-liquid processes between geogenic materials, dust or soils, and the human body in order to explain to the medical community. These contributed to the recognition of mechanisms responsible for several health maladies, the growth of a new geochemical branch, Medical Geochemistry.

This book is provided for students and researchers (chemists, geologists, geochemists, environmental scientists) Medical Geochemistry. The chapters in this lectures that the authors the Summer School on Medical Geochemistry at the Institute of the Coastal Marine Environment of Italian National Research Council (IAMC-CNR) in Capo Granitola (Italy) the University of Palermo and CNR with the aid of Regione Sicilia and contributions of Thermo Scientific and Bruker Corporation Italia.

Related to the human exposure interactions with geogenic solids, the structure of this book is based on eight chapters regarding the inhalation of suspended solids and their dissolution in contact with lung fluids; effects of the biological, geographical, dietary, and environmental exposure histories on the compositions of human bones; the origin of source materials of potentially inhaled atmospheric dust; biological effects on crystallization of newly formed minerals; mineralogical techniques exploited to investigate newly formed biominerals under physiological conditions; and trace element accumulations in hairs as a consequence of the human environmental exposure, rigorous assessment of the applied to data.

University of Palermo, Palermo, Italy

Paolo Censi

Duke University, Durham, USA

The Hebrew University of Jerusalem, Jerusalem, Israel

Thomas H. Darrah

Yigal Erel 



\section{Contents}

1 Using the Trace Element Contents in Bronchoalveolar Lavages to Probe the Human Exposure to Inhaled Particulates ..... 1 Paolo Censi, E. Tamburo, L.A. Randazzo, Pierpaolo Zuddas, Angela Cuttitta, and Thomas H. Darrah

2 Geochemistry and Biochemistry: Insights into the Fate and Transport of Pt-Based Chemotherapy Drugs

Robyn E. Hannigan and Thomas H. Darrah

3 Atmospheric Particulate Matter (PM) in the Middle

East: Toxicity, Trans-boundary Transport, and Influence of Synoptic Conditions

Yigal Erel, O. Tirosh, N. Kessler, U. Dayan, S. Belkin,

M. Stein, A. Sandler, and J.J. Schauer

4 Reaction Path Modeling: Theoretical Aspects and Applications ......

L. Marini

5 An Observation on the Composition of Urinary Calculi: Environmental Influence

Maria Luigia Giannossi and Vito Summa

6 Magnetite Minerals in the Human Brain: What Is Their Role?

Pierpaolo Zuddas, D. Faivre, and J.R. Duhamel

7 Chemometrics and Medical Geochemistry: A Brief Tutorial Robyn E. Hannigan

8 Dust, Metals and Metalloids in the Environment: From Air to Hair . Gaetano Dongarrà, E. Tamburo, and D. Varrica 
9 Metal Geochemistry of a Brackish Lake: Étang Saumâtre, Haiti..... 149 Alex Eisen-Cuadra, Alan D. Christian, Emmanis Dorval, Bryanna Broadaway, Josi Herron, and Robyn E. Hannigan

10 Trace Element Composition of Modern Human Bone 167 Thomas H. Darrah, M. Ellen Campbell, Jennifer J. Prustman-Pfeiffer, Robert J. Poreda, and Robyn E. Hannigan

Index 